\title{
Perspective of Healthcare Providers using \\ Reproductive Smart Mobile Application in Jakarta: A Qualitative Study
}

Budi Wiweko ( $\nabla$ wiwekobudi@yahoo.co.id)

Faculty of Medicine, Universitas Indonesia https://orcid.org/0000-0002-5898-7034

Aida Riyanti

Universitas Indonesia

Shanty Olivia

Universitas Indonesia

Muhammad Priangga

Universitas Indonesia

Vita Silvana

Universitas Indonesia

Sarah Chairani Zakirah

Universitas Indonesia

llonna Putri Pertiwi

Universitas Indonesia

Anggi Lewis Reso Putro

Universitas Indonesia

Yohanes Satrya Wibawa

Universitas Indonesia

Achmad Kemal Harzif

Universitas Indonesia

\section{Gita Pratama}

universitas indonesia

Kanadi Sumapraja

universitas indonesia

R. Muharam

universitas indonesia

Andon Hestiantoro

universitas Indonesia 
Keywords: Reproductive Health, Health Services, Medical Informatics, Application

Posted Date: February 26th, 2020

DOl: https://doi.org/10.21203/rs.2.24558/v1

License: (c) (1) This work is licensed under a Creative Commons Attribution 4.0 International License. Read Full License 


\section{Abstract}

Objective : Our study aimed to evaluate the perspectives of health care providers of JAKPROS ( Jakarta Reproduksi Sehat ) application that is used to improve the maternal health service. This descriptive qualitative study engaged 16 healthcare providers from two sub-district hospitals. The participants were selected using purposive sampling and cross-sectional design. Participant were asked to fill the written informed consent.Data were collected by in-depth discussion of a list of selected questions in a focus group discussion.

Results: Most health care providers used paper-based systems in their hospitals. They said that it was very helpful in helping them communicate with their patients and provide information. The application has many benefits that help doctors provide the best service for patients during pregnancy.The use and adoption of app is needed to make a further improvements in the healthcare system. This study will help improve the application for more widespread use in a greater number of hospitals. JAKPROS made healthcare provider easier to communicate and track patient's health. This app also assist patients related to the doctor's schedule, health information, and nearest hospital.

\section{Introduction}

Paper-based medical record keeping for health services has several limitations - for example, it is limited in its ability to connect a doctor to his patient (1). To date, there are few studies in Indonesia regarding electronic-based application that have been implemented in daily services. An electronic-based application is needed to improve dynamic communication among healthcare provider and community. In 2018, we designed JAKPROS (Jakarta Reproduksi Sehat) application, a smart mobile application for healthcare provider and community. These application was developed to improve women's health service, especially in Jakarta. It has several features that will help the healthcare provider to give the best service. Firstly, the educational page helps the patient to get reliable information on reproductive health from experts. Secondly, the question and answer section connects the doctor to the patient in order to provide fast responses to patients' questions (Fig. 1). The hospital page and schedule page helps patients access the nearest hospital and the doctor's schedule. Lastly, doctors can monitor their patients' medical records - for example, tracking the blood pressure of a pregnant patient. This qualitative study aimed to explore healthcare providers perspective of the application regarding application improvement in assisting healthcare provider-patients dynamic relationship of health care service.

\section{Methods}

Healthcare providers were enrolled by IPP from two different hospitals in different sub-district areas in Jakarta, such Tanah Abang Hospital and Tanjung Priok Hospital. Data were obtained on September 2018 within 2 weeks. Participants were explained about the study before study enrollment. Data were collected through focus group discussion and direct observation of the participants. We used purposive sampling in order to meet the inclusion criterias. The inclusion criteria were health care providers (general 
practitioner, obstetrics and gynecology specialist, midwife or nurse), had participated in our previous quantitative study, have a mobile phone, have been using the application for at least 2 weeks, have the ability to express their inner feelings and emotions, their experiences and their innate interest in expressing their experience (2). Participants were also asked to fill written informed consent and assured for confidentiality and anonymity. Participants were free to withdraw themselves at any time without prepossession.

This study was used three common methodologies in qualitative study, such as, ethnography, Van Manen's phenomenology, and grounded theory. Ethnography study was done by direct observation method which allows us to observe the real situation in working environment. The second one was phenomenology which is a study placing researcher in participant's view to understand the meaning of their experiences. This methodology gathers data through in-depth interviews with semi-structured openended questions addressed to the participants. In this regard, we used Van Manen's methodological approach as a manner to understand of lived experience thoroughly and act more reflectively. The last one was grounded theory which means the study was done using face-to-face interview and direct interactions, such as a focus group discussion $(3,4)$.

A semi structure interview guide (Table 1) was used to obtained the perspective of healthcare provider. Interview guide was developed according to our previous questionnaire from quantitative study and the current situation of each health care center (2). These questionnaire was integrated from the expert from obstetrician and gynaecologist and the content of the application respect to the mobile facilities provided to health care provider.

Table 1

Interview guide for health care provider

\section{Describe the current health service system in your hospital? Is it paper-based or electronic-based system?}

Tell me your perspective about paper-based health service system?

What should be done for better health service system?

Tell me the benefit of Jakpros application for health service system in your perspective?

We had a quantitative study about JAKPROS application to collect patient's perspective information. We explained about the application to the patients and the healthcare providers. After we collected the data from the patients, we ask the healthcare provider to use the application within 2 weeks to evaluate the application regarding the information and the features for them. Two weeks later, we conducted a focusgroup discussion and face-to-face interviews at the same moment. Results were obtained from a single 90-minutes (5). Each question was not asked to all of the participants during interview because of the similar participant's characteristic. However, we provided each question to the focus group discussion and discussed it together. Face-to-face interviews were allowed to explore the detail information from 
individual. We also used field notes to amplify the data information. However, we did not find any specific important information during data retrieval.

Major theme of this study was about the perspectives of participants respect to the using mobile health application. Minor theme was mobile health application benefit to health care service. We asked the participants about their experiences on paper-based service systems and application benefits to health service system. In the discussion, we asked the participants some questions (Table 1) and emphasized that there were no right or wrong answers. Data were audio recorded, transcribed, and coded by IPP (a general practitioner), AR (a gynecologist), and SO (a gynecologist) to enhance the data validity and reliability.

After collected and transcribed the data, IPP, AR, and SO compared and discussed their findings and analyses. Data saturation and inductive analysis were done by each coder to bring up the themes. We derived the key-themes into several section, such as the current health system facts, the healthcare provider's perspective regarding paper-based health service system, the suggestion from healthcare provider for a better health service system, and the benefit of Jakpros application usage respect to the health service system.

\section{Results}

\section{Characteristics of participants}

Sixteen women healthcare providers were involved in this study. All of participants aged 25 to 50 years old. Participants had a range of professions such as 1 general practitioner, combination of 15 nurses and midwifes. No participant refused to attend the interviewer forum or withdrew the consent. We did not obtain specific finding related to the participant's characteristic. Main finding in this study is the general perspective of healthcare providers respect to the large system development in healthcare facilities according to the current digitalization era.

\section{Key-themes}

Key themes were derived from thematic analysis of the observation of paper-based health service system difficulties, such as:

- Health care provider perpectives- current health service system, perspective of paper-based health service system, and suggestion for better health service system

- Application to improve maternal health service

\section{Health Care Provider Perspectives}




\section{Current Health Service System}

Most respondents said that their hospitals still used a paper-based health service system, including for patient registration. Registration with paper-based have some limitations, such as a long waiting-list of patients, requiring many officers, and discordant information by handwriting. Furthermore, diligence is need to maintain medical record, in which loss of a paper is often happen. Pharmacist with paper-based is also prone human error in reading handwriting. Drug name, dosage, and patient's characteristic are the important information for patient's safety (Table 2).

Table 2

Key themes-Health care provider perspectives and JAKPROS application

\section{Health care provider perspective}

Current health

service system
We are still using the same system like before, we do not have an online system for patient to register. (nurse)

We use paper-based medical records and have to complete them on a paper. (midwife)

We did not have any online systems, it's all paper-based. (nurse)

Billing is the only online system in our hospital.(nurse)

Perspective of paper-based health service system

Our budget for more change is limited.(midwife)

We can handle it because we have just a few patients.(midwife)

The old one prevent us to serve the best for patients. But we can't do anything about it. (nurse)

Large scale changes are needed in our hospital system before we can make changes at this level. (midwife)

Budget is required excessively (midwife)

Suggestion for better health service system
Paper-based medical record is less helpful in improving communication between doctor and patient, in which online system might be required to make better decisions. (nurse)

We need better communication with our patients. (nurse)

Familiarity with the latest technology is required to improve the health service. (nurse)

It would be better if we used online systems to track our patients. (nurse)

JAKPROS

Application

Jakpros Application

We could easily tracking our patient but we still improve it for daily (General practitioner)

The doctor schedule helps patients know that they do not have to call our customer service. (nurse)

The patient is interested in asking their doctor questions. (midwife)

An online medical record is required to make it easier to follow up the patient in hospital. (midwife)

\section{Perpectives Of Paper-based Health Service System}


Our study locations were government hospitals. Respondents said that systems had not been updated due to budget constraints. One respondent said that, as their hospital had a few patients, the system was still under control so that changing was not required yet. According to paper-based health service system, patients also have to wait a long time for registration. Because the healthcare provider must search their medical records and write up the paper-based record. Most of them thought that change was required for a better health service. (Table 2)

\section{Suggestion For Better Health Service System}

Healthcare providers agreed that hospital improvements such as increased use of digital technology are required to provide the best service for the patient. This would enable improvements in the other areas of health service to achieve broader goals. Paper-based medical record makes difficulty in communication between doctor and patient. An online system might be required for providers to make better decisions. (Table 2)

\section{Application To Improve Maternal Health Service}

This study showed that the application was made them easier in providing a better service. According to respondents, mobile health applications will help them in providing information and maintaining medical records. Healthcare providers in our study agreed that there was a maternal health service improvement. The application is a breakthrough in service provision. Dynamic communication and decision making between healthcare provider and patients can be done through this application. This was in line with a previous study that healthcare providers felt easier in providing health service by using internet-based service (8)

A study conducted by Allen-Graham and colleague obtained that using electronic health record increased fault probability. Results have shown that discordant information in hospital medical record may expose patients to harm. Some issues have to be addressed regarding electronic health record, such as little uniformity in clinical information system, health care information detail by each provider is various when capturing, storing, and using those information, and variability of each medical information makes discordant information (9). Previous study also stated that electronic system was associated with greater severity of medical error regarding polypharmacy and co-use of drugs in the same patient compared to paper-based system during pharmacovigilance. However, electronic system prevents fault of technical affairs, such as physician's bad handwriting or similar drugs that might cause prescription's error. Hinojosa-Amaya and colleague stated that the use of electronic system was associated with a reduction in medical error with OR $0.59(95 \% \mathrm{Cl}: 0.41-0.85)(10)$. Data transfer accuracy was also significantly improved by using mobile-based compared to paper-based system (11).

Intervention of mHealth was shown patient's perceived improvement in quality of service. A study in Afghanistan by using mobile application showed significant improvement for consumer and health care 
provider when dealing with health decision making and health seeking behavior (12). Mobile application also made healthcare provider easy in providing health service, such as referral coordination. Healthcare providers agreed that this was a helpful application for daily service. This study would be beneficial for further development of the application.

\section{Discussion}

\section{Health care provider perspectives}

Although changing paper-based to electronic-based health service system might increase cost-utilization of hospital in the first development period, it should be recognized that electronic-based service system can make healthcare provider easier in providing service to patients. Cost-effectiveness also should be addressed in each center respect to the paper usage.

One of the examples of paper-based service system is paper-based health record which only available in one copy, written on paper, and maintained in subsection specific folder. Paper-based health record also have the other limitations, such as probability to be misplaced or missed data due to oversight of healthcare provider. Furthermore, data record overlapping in different location and data extracting difficulties for research are also the adversity of electronic health system. While strengthening and training of healthcare provider are the things that have to be done, it may significantly lowering patient charges and hospital costs $(6,7)$.

\section{Application to Improve Maternal Health Service}

This study showed that the application was made them easier in providing a better service. According to respondents, mobile health applications will help them in providing information and maintaining medical records. Healthcare providers in our study agreed that there was a maternal health service improvement. The application is a breakthrough in service provision. Dynamic communication and decision making between healthcare provider and patients can be done through this application. This was in line with a previous study that healthcare providers felt easier in providing health service by using internet-based service (8)

A study conducted by Allen-Graham and colleague obtained that using electronic health record increased fault probability. Results have shown that discordant information in hospital medical record may expose patients to harm. Some issues have to be addressed regarding electronic health record, such as little uniformity in clinical information system, health care information detail by each provider is various when capturing, storing, and using those information, and variability of each medical information makes discordant information (9). Previous study also stated that electronic system was associated with greater severity of medical error regarding polypharmacy and co-use of drugs in the same patient compared to paper-based system during pharmacovigilance. However, electronic system prevents fault of technical affairs, such as physician's bad handwriting or similar drugs that might cause prescription's error. 
Hinojosa-Amaya and colleague stated that the use of electronic system was associated with a reduction in medical error with OR 0.59 (95\% Cl: 0.41-0.85) (10). Data transfer accuracy was also significantly improved by using mobile-based compared to paper-based system (11).

Intervention of mHealth was shown patient's perceived improvement in quality of service. A study in Afghanistan by using mobile application showed significant improvement for consumer and health care provider when dealing with health decision making and health seeking behavior (12). Mobile application also made healthcare provider easy in providing health service, such as referral coordination. Healthcare providers agreed that this was a helpful application for daily service. This study would be beneficial for further development of the application.

\section{Limitations}

- This study was not asking the participant's feedback and using qualitative analysis software that will decrease the validity and reliability of the findings.

- The participants used the application only within 2 weeks, which might not be long enough for them to use all the features. However, we also conducted quantitative analysis and had the same results for patient's perspective. The result showed that the application had described the tendency of each participant's answers.

\section{Abbreviations}

JAKPROS

Jakarta Reproduksi Sehat

\section{Declarations}

\section{Ethics Approval and Consent to Participate}

This study was approved by Ethical Committee of Health Research. Faculty of Medicine Universitas Indonesia, Dr. Cipto Mangunkusumo General Hospital; Committee reference number :

1327/UN2.F1/ETHIC/2018). Every participant included in this study agreed to be included in focus group discussion

\section{Consent to Publish}

Applicable for under a pseudonym of each participant 


\section{Availability of data and material}

The data that support the findings of this study are available from Sarah Chairani Zakirah, MD, but restrictions apply to the availability of these data, which were used under license for the current study, and so are not publicly available. Data are however available from the authors upon reasonable request and with permission of Sarah Chairani Zakirah, MD.

\section{Competing interest}

The authors declare that they have no competing interests. Written informed consents were obtained from each participant before study enrollment.

\section{Funding}

This research publication is supported by the United States Agency for International Development (USAID) through the Sustainable Higher Education Research Alliance (SHERA) Program for University of Indonesia's Scientific Modeling, Application, Research, and Training for City-centered Innovation and Technology (SMART CITY) Project, Grant \#AID-497-A-1600004, Sub Grant \#IIE-00000078-UI-1.

\section{Authors contribution}

All authors have read and approved the manuscript. BW, AR, SO, MP, VS : Conceptualization; Data curation; Formal analysis; Funding acquisition; Investigation; Methodology; Project administration; Resources; Supervision; Validation. IPP : Data curation, Formal analysis, Investigation; Methodology; Project administration; Resources; Software; Visualization; Roles/Writing - original draft; SCZ : Formal analysis, Investigation; Methodology; Project administration; Resources; Software; Visualization; Roles/Writing - original draft; Writing - review \& editing. ALP, YSW : Visualization. AKH, GP, KS, RM, AH : Conceptualization, Resources; Supervision; Validation.

\section{Acknowledgment}

The authors thank Ann Seward, ELS, of AuthorAID, for English-language assistance with an early draft of the manuscript, and Enago proof-reading services.

\section{Author details}


${ }^{1}$ Indonesian Medical Education and Research Institute - Human Reproductive, Infertility, and Family Planning Cluster, Faculty of Medicine Universitas Indonesia, Jakarta; Dr. Cipto Mangunkusumo General Hospital, Jakarta, Indonesia; ${ }^{2}$ Yasmin IVF Clinic, Dr. Cipto Mangunkusumo General Hospital, Jakarta, Indonesia; ${ }^{3}$ Division of Reproductive Endocrinology and Infertility Department of Obstetrics and Gynecology, Faculty of Medicine Universitas Indonesia; Dr. Cipto Mangunkusumo General Hospital, Jakarta, Indonesia. Email: (1) wiwekobudi@yahoo.co.id, (2) aidatx2004@hotmail.com, (3) shantyolivia.fj@gmail.com, (4) angga.mdp@gmail.com, (5) vita.silvana@yahoo.com, (6) sarahchairani@gmail.com (7) ilonnaputri23@gmail.com, (8) lewisaruan@gmail.com, (9) drsatryawibawa@gmail.com, (10)kemal.achmad@gmail.com, (11) gitapratama@yahoo.com, (12) kanadisuma@yahoo.com; (13)r.muharam@yahoo.com, (14) hestiantoro@gmail.com

\section{References}

1. Sinha Deb K, Tuli A, Sood M, Chadda R, Verma R, Kumar S, et al. Is India ready for mental health apps (MHApps)? A quantitative-qualitative exploration of caregivers' perspective on smartphone-based solutions for managing severe mental illnesses in low resource settings. Soundy A, editor. PLoS One. 2018 Sep 19;13(9):e0203353.

2. Wiweko B, Riyanti A, Olivia S, Priangga M, Silvana V, Pertiwi IP, et al. Jakpros: Reproductive health education application for pregnant women. 2018 Int Conf Adv Comput Sci Inf Syst ICACSIS 2018. 2019;225-9.

3. Errasti-ibarrondo B, Jordán JA, Díez-del-corral MP, Arantzamendi M. van Manen 's phenomenology of practice: How can it contribute to nursing? 2019;(June 2018):1-10.

4. Sutton J, Austin Z. Qualitative research: Data collection, analysis, and management. Can J Hosp Pharm. 2015;68(3):226-31.

5. Altman L, Zurynski Y, Breen C, Hoffmann T, Woolfenden S. A qualitative study of health care providers' perceptions and experiences of working together to care for children with medical complexity (CMC). BMC Health Serv Res. 2018;18(1):1-11.

6. Evans RS. Electronic Health Records: Then, Now , and in the Future. 2016;48-61.

7. Zhang XY, Zhang P. Recent perspectives of electronic medical record systems ( Review ). 2016;20835.

8. Vélez O, Okyere PB, Kanter AS, Bakken S. A Usability Study of a Mobile Health Application for Rural Ghanaian Midwives. J Midwifery Womens Health. 2014 Mar;59(2):184-91.

9. Allen-Graham J, Mitchell L, Heriot N, Armani R, Langton D, Levinson M, et al. Electronic health records and online medical records: An asset or a liability under current conditions? Aust Heal Rev. 2018;42(1):59-65.

10. Hinojosa-Amaya JM, Rodríguez-García FG, Yeverino-Castro SG, Sánchez-Cárdenas M, VillarrealAlarcón MÁ, Galarza-Delgado DÁ. Medication errors: electronic vs. paper-based prescribing. Experience at a tertiary care university hospital. J Eval Clin Pract. 2016;22(5):751-4. 
11. Balakrishnan R, Gopichandran V, Chaturvedi S, Chatterjee R. Continuum of Care Services for Maternal and Child Health using mobile technology - a health system strengthening strategy in low and middle income countries. BMC Med Inform Decis Mak [Internet]. 2016;1-8. Available from: http://dx.doi.org/10.1186/s12911-016-0326-z

12. Bauer AM, Rue T, Keppel GA, Cole AM, Baldwin L-M, Katon W. Use of Mobile Health (mHealth) Tools by Primary Care Patients in the WWAMI Region Practice and Research Network (WPRN). J Am Board Fam Med. 2014 Nov 1;27(6):780-8.

\section{Figures}

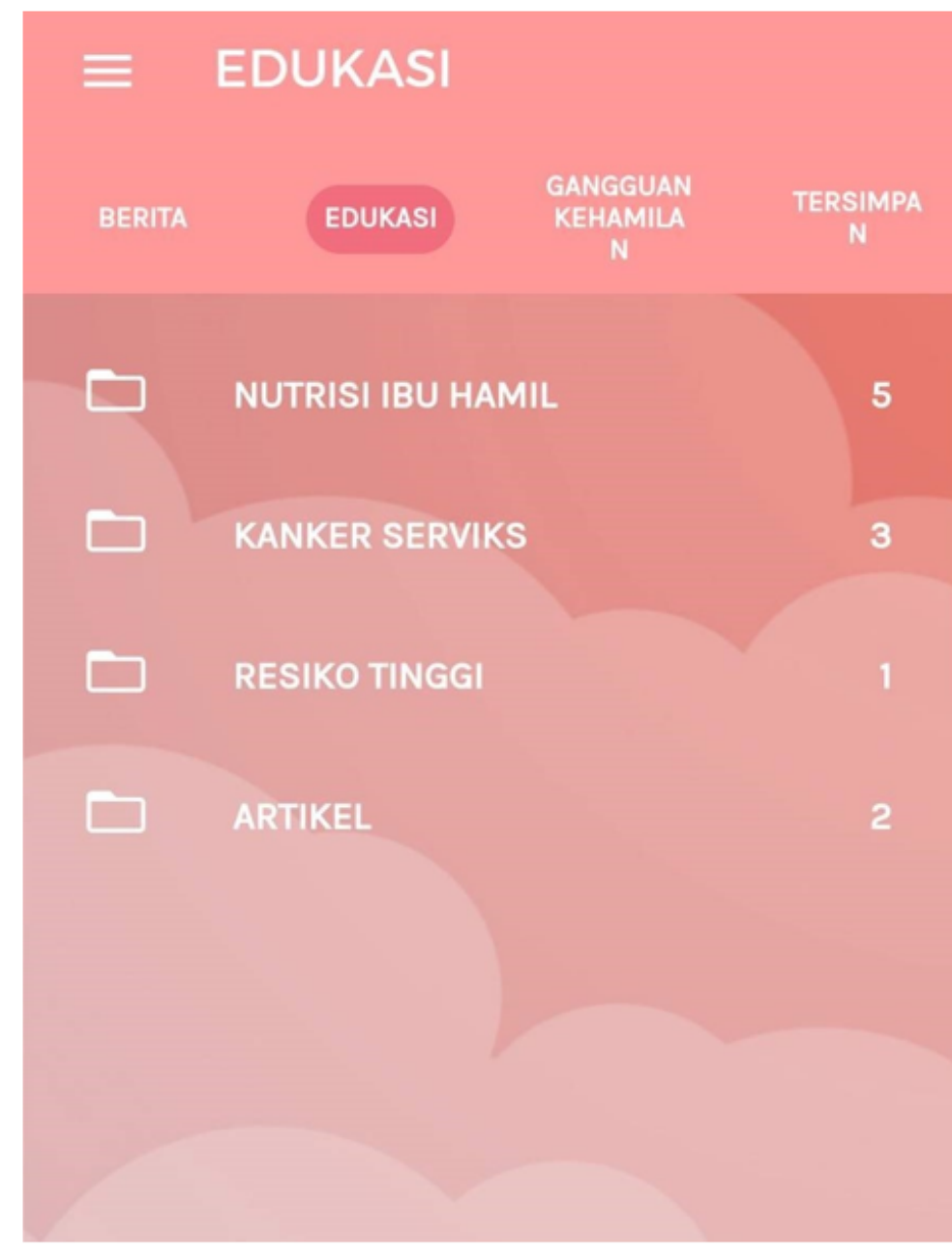

A

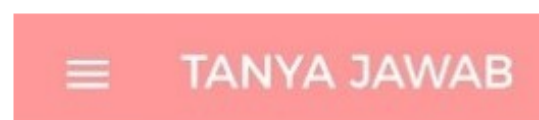

BPJS UNTUK KEHAMILAN

Tanya Jawab terkait fasilitas BPJS

yang ada di RSUK

1 PERTANYAAN

1 TERJAWAB

KESEHATAN IBU HAMIL

Jaga Kesehatan ibu hamil dan buah

hati

11 PERTANYAAN

O TERJAWAB

PENYAKIT KRONIS PADA IBU HAM

Tanya jawab terkait penyakit kronis

yang diderita Ibu Hamil

3 PERTANYAAN

O TERJAWAB

PERSIAPAN KEHAMILAN

Selalu siap dimanapun dan

kapanpun

2 PERTANYAAN

O TERJAWAB

\section{Figure 1}

(A) Educational page of the application; (B) Question and answer section 